\title{
Millet Phenolics as Natural Antioxidants in Food Model Systems and Human LDL/VLDL Cholesterol in vitro
}

\author{
K.D.D. Kumari, W.M.T. Madhujith ${ }^{1}$ and G.A.P. Chandrasekara ${ }^{2^{*}}$ \\ Postgraduate Institute of Agriculture \\ University of Peradeniya \\ Sri Lanka
}

\begin{abstract}
Dehulled grain flour of finger millet (Eleusine coracana), proso millet (Panicum miliaceum) and foxtail millet (Setaria italica) and phenolic extracts of millet hulls were evaluated for ability to inhibit lipid oxidation in several food model systems, namely cooked comminuted pork and fish, roasted peanut butter and gingelly oil. Food samples were kept for 14 days with added millet hull extracts and dehulled grain flours. The percentage inhibition of production of thiobarbituric acid reactive substances (TBARS) during storage was determined. Inhibitory activities of phenolic extracts of finger millet dehulled grain and finger millet foods, namely, Rotti, Pittu, Halapa, Thalapa and porridge, against human very low-density lipoprotein (VLDL) and low-density lipoprotein (LDL) oxidation were determined by measuring the production level of conjugated dienes (CD) in vitro. Finger millet had higher phenolic content and antioxidant activities compared to the respective proso and foxtail millet samples. Finger millet hull extracts exhibited the highest inhibition of lipid peroxidation in food model systems. The maximum percentage inhibition of TBARS in pork, fish, and peanut with added finger millet hull extracts were observed at days 3, 7, 5, and 14, respectively. The percentage inihibition of TBARS in cooked pork and fish with added millet hull extracts ranged from 4.4 to $12.8 \%$ and 63 to $77 \%$, respectively at the end of the second week. Millet grains and desolventized millet phenolic extracts can act as natural sources of antioxidants at different degrees in pork, fish, peanut and gingelly oil to prevent lipid oxidation during storage.
\end{abstract}

Keywords: Lipid oxidation inhibition, millet, natural antioxidants, meat, gingelly oil, roasted peanut butter

\section{INTRODUCTION}

Lipid oxidation products formed in foods lead to the development of off-flavours and affect nutritional and sensory qualities. Further, they act as atherogenic agents in addition to their mutagenic and carcinogenic properties (Shahidi et al., 2012). Polyunsaturated fatty acids (PUFA) in foods are susceptible to oxidation during processing and storage (Shahidi et al., 2012). A number of factors affects the rate of lipid oxidation in foods. Special measures are taken during processing and storage to prevent food lipid oxidation and addition of antioxidants is a common practice among others. Butylated hydroxyanisole (BHA), butylated hydroxytoluene (BHT) and tert-butyl hydroquinone (TBHQ) are most widely used synthetic antioxidants in food industry (Shahidi and Zhong, 2005). There are several controversies in

1 Department of Food science and Technology, Faculty of Agriculture, University of Peradeniya, Sri Lanka

2 Department of Applied Nutrition, Wayamba University of Sri Lanka, Makandura, Gonawila, Sri Lanka

* Corresponding author: anomapriyan@yahoo.ca 
the use of synthetic antioxidants as health concerns have been raised on their addition in foods )Shahidi and Zhong, 2005). Food additives are subjected to the most stringent toxicological testing procedures, and only a few synthetic antioxidants have been used in foods so far. There is a growing interest of using natural antioxidants in foods. The natural antioxidants include phenolic compounds, tocopherols, and flavonoids (Artajo et al., 2006). Oxidized Low-density lipoproteins (LDLs) have been detected in atherosclerotic vessels and they appear to play a major role in the disease process (Esterbauer et al., 1992; Steinberg, 1992). Naturally occurring antioxidants in the diet may play a role in inhibiting the oxidative modification of LDL and hence they might act as anti-atherosclerotic agents (Shahidi et al., 2012)

Millets are recognized as potential future crops due to their nutrient contents similar to other major cereals and rich non-nutrient profiles, especially phenolic compounds )Shahidi and Chandrasekara, 2014; Kumari et al., 2017). Previous work on millets have proven that phenolic compounds present in millets are bioaccessible and may act as antioxidants within the human body to protect against oxidative stress (Chandrasekara and Shahidi, 2012a). The aim of the present work was to evaluate the ability of millet phenolic compounds to prevent the oxidation of lipids present in food model systems namely, pork, fish, peanut, and gingelly oil and to determine the ability of millet phenolics to prevent the oxidation of human LDL cholesterol in vitro.

\section{METHODOLOGY}

Samples of finger millet (Elusine coracana) variety "Oshada", local variety of proso millet (Panicum miliacium) and foxtail millet (Setaria italica) grown in Sri Lanka were used in this study. All grain materials were obtained from the Department of Agriculture, Sri Lanka. FolinCiocalteu's reagent was purchased from Research Lab Fine Chem Industries, Mumbai, India. Vanillin, 2,2-diphenyl-1-picrylhydrazyl (DPPH), 2,2 azinobis (3-ethylbenzothiazoline-6sulfonate diammonium salt) (ABTS), 2,2-azobis (2-methylpropionamidine) dihydrocholride (AAPH), ferrous chloride, sodium chloride, butylated hydroxyanisole (BHA), ferulic acid, trolox, catechin, and ethanol were purchased from Sigma-Aldrich, St Louis, USA. Sodium carbonate, ferric chloride, were purchased from Thomas Baker (Chemicals) Limited, Bombay, India. Aluminium chloride, trichloroacetic acid (TCA), and potassium phosphate dibasic were purchased from Techno Pharm Chem, India. Sodium hydroxide, and potassium phosphate monobasic were purchased from Loba Chem Pvt Ltd, India. 3-(2-pyridyl)-5,6-diphenyl-1,2,4triazine-4,4-disulfonic acid sodium salt (Ferrozine) were purchased from SERVA Electrophoresis $\mathrm{GmbH}$, Heildberg, Germany. Ethylene diamine tetra acetic acid tri sodium salt ( $\mathrm{Na}_{3}$ EDTA) was purchased from Needham Market Sufflock, England. 2, 2, 4trimethylpentane and 1,1,3,3-tetramethoxypropane were purchased from Sigma-Aldrich, St Louis, USA.

\section{Sample preparation}

Millet whole grains were dehulled and hulls were separated from grains. Finger millet grains were dehulled using a rice polishing machine (Rice husker and polisher PM 500, Satake Engineering Co Ltd, Japan). Foxtail millets and proso millets were dehulled using rice milling machine (Rice machine, Satake Engineering Co Ltd, Japan). Dehulled grains, and hulls were separately used for the extraction of phenolics. Samples were ground using an electric grinder and sieved (0.038 seive opening; As 200 test seiver, Retsch, Germany). Samples were defatted using hexane (1:5 w/v, 2 min, two times) at ambient temperature. Defatted samples packed in 
polythene pouches were stored at $-80{ }^{\circ} \mathrm{C}$ until used within a week for extraction of phenolic compounds.

\section{Extraction of soluble phenolic compounds}

Soluble phenolic compounds were extracted from dehulled grains and hulls of millets. Defatted meal $(5 \mathrm{~g})$ was mixed with $100 \mathrm{~mL}$ of $80 \%$ (v/v) aqueous ethanol in a capped conical flask and placed in a shaking water bath at $50^{\circ} \mathrm{C}$, stirring at $175 \mathrm{rpm}$ speed for 40 minutes. The extraction procedure was repeated two more times. Combined supernatants were evaporated in rotary evaporator at $40^{\circ} \mathrm{C}$ at $125 \mathrm{rpm}$. Concentrated samples were freeze dried at $-55^{\circ} \mathrm{C}$, and $12 \times 10^{-}$ ${ }^{3}$ mbar. Lyophilized crude phenolic extracts were stored at $-80^{\circ} \mathrm{C}$ until used for further analysis. During all stages, extracts were protected from light by covering with aluminum foil.

\section{Determination of oxidative stability in comminuted pork model}

The samples were prepared to determine the oxidative stability of dehulled millet flour and soluble phenolic extracts of millet hull according to Chandrasekara and Shahidi (2012b). In brief, ground pork $(80 \mathrm{~g})$ was mixed with $20 \mathrm{~g}$ deionized water in a glass jar and mixed with testing materials, namely dehulled millet flour $(2 \%)$, hull phenolic extracts $(0.2 \%)$, ferulic acid $(0.02 \%)$ or BHA $(0.02 \%)$ followed by thoroughly mixing with a glass rod. A control without added compounds was maintained under same experimental conditions. Capped glass jars were cooked in a water bath at $80 \pm 2{ }^{\circ} \mathrm{C}$ for 40 minutes while stirring with a glass rod at every 5 minutes. Samples were cooled to room temperature and were transferred to polythene bags. Bags were stored in a refrigerator at $4{ }^{\circ} \mathrm{C}$ and samples were drawn on days $0,3,5,7$ and 14 for the analysis of thiobarbituric acid reactive substances (TBARS). The experiment of each test material was carried out in three replications.

\section{Determination of oxidative stability in fish model}

The oxidative stability of dehulled millet grains and soluble phenolic extracts in the inhibition of TBARS production in cooked Tuna fish (ground boneless flesh) was determined as previously explained (Wijeratne et al., 2006). The experimental procedure was similar to the pork model explained in the previous section.

\section{Determination of oxidative stability in peanut model}

The effect of dehulled millet grain and soluble phenolic extracts in the inhibition of TBARS production in roasted ground peanut was determined according to Wijeratne et al. (2006). Dehulled millet flour $(2 \%)$, phenolic extracts of hulls $(0.2 \%)$, ferulic acid $(0.02 \%)$ and BHA $(0.02 \%)$ were added to $100 \mathrm{~g}$ of ground peanut and thoroughly mixed with a glass rod in a glass jar. A separate control sample without extracts was also prepared. Samples were mixed thoroughly and transferred into polythene bags. Samples were stored in room temperature for 14 days. Samples were drawn on days $0,3,5,7$ and 14 for analysis of TBARS.

\section{Determination of oxidative stability in gingelly oil}

The efficacy of soluble millet extracts to inhibit the oxidation of gingelly oil was measured according to the method explained by Chandrasekara and Shahidi, (2011b). Hull phenolic extracts (1\%), ferulic acid (1\%) and BHA (1\%) were added separately into $100 \mathrm{~mL}$ glass jars, and then $2 \mathrm{~g}$ of gingelly oil sample was added following vortexing thoroughly for 2 minutes. Each treatment was prepared in triplicate and jars were kept in the oven at $60^{\circ} \mathrm{C}$. Samples for 
the analysis of TBARS were drawn on $0,6,12,24,36$ and 48 hours and were analyzed for the inhibition percentage of TBARS and the production of conjugated dienes (CD). Control samples of oil without test materials were maintained under identical experimental conditions.

\section{Inhibition percentage of TBARS}

The inhibition percentage of TBARS was determined according to the method explained by Chandrasekara and Shahidi, (2012b). In this, $2 \mathrm{~g}$ from each fish, meat, or peanut sample was weighed in a $50 \mathrm{~mL}$ centrifuge tube. Then $5 \mathrm{~mL}$ of $10 \%$ (w/v) solution of trichloroacetic acid (TCA) were added and vortexed at high speed for 2 minutes. Thiobarbituric acid (TBA) solution $(0.02 \mathrm{M}, 5 \mathrm{~mL})$ was added to each centrifuge tube and vortexed for 30 seconds. The samples were subsequently centrifuged at $3000 \mathrm{~g}$ for 10 minutes and the supernatants were filtered through a Whatman No.3 paper. Filtrates were heated in a boiling water bath for 45 minutes and cooled to room temperature on an ice bath. The absorbance of the pink coloured chromogen was measured at $532 \mathrm{~nm}$ (UV-VIS Spectrophotometer, Labomed Inc, USA). Standard curve was prepared using 1,1,3,3-tetramethoxypropane as a precursor of the malondialdehyde (MDA). The percentage inhibition of TBARS formation was calculated as follows. Inhibition percentage $=\left\{\left(\right.\right.$ TBARS control $_{\text {TBARS }}$ sample $) /$ TBARS $\left._{\text {control }}\right\} \times 100$, where TBARS control $=$ TBARS formed in the control and TBARS sample $=$ TBARS formed in the sample. TBARS values of oil samples were determined according to the standard AOCS method. In brief the oil $(50-100 \mathrm{mg})$ was weighed into a $25 \mathrm{~mL}$ volumetric flask and made up to volume with 1-butanol. Then $5 \mathrm{~mL}$ of this solution was transferred into a screw capped test tube with added $5 \mathrm{~mL}$ of freshly prepared 2 -TBA reagent $(500 \mathrm{mg}$ of TBA in $250 \mathrm{~mL} \mathrm{1-}$ butanol). Contents were thoroughly mixed and heated in a water bath at $95^{\circ} \mathrm{C}$ for 2 hours. Samples were cooled in an ice bath and the absorbance values were measured at $532 \mathrm{~nm}$. Standard curve was prepared using 1,1,3,3-tetramethoxypropane as a precursor of the malondialdehyde (MDA). The percentage inhibition of TBARS formation was calculated as follows. Inhibition percentage $=\left\{\left(\right.\right.$ TBARS control $_{\text {TBARS }}$ sample $) /$ TBARS control $\} \times 100$, where TBARS control $=$ TBARS formed in the control and TBARS sample $=$ TBARS formed in the sample.

\section{Determination of conjugated diene (CD) in gingelly oil sample}

The CD contents of oil samples were determined according to the method explained by Shahidi and Zhong (2005). In this a sample of gingelly oil $(0.02-0.03 \mathrm{~g})$ was weighed into a $25 \mathrm{~mL}$ volumetric flask, and made up to the mark with 2,2,4-trimethylpentane. The solution was thoroughly mixed and the absorbance was measured at $234 \mathrm{~nm}$. Pure 2, 2, 4- trimethylpentane was used as a reference. $\mathrm{CD}$ values were calculated using the following equation; $\mathrm{CD}=$ Absorbance of solution at $234 \mathrm{~nm} / \mathrm{C} * \mathrm{~L}$, where $\mathrm{C}=$ concentration of oil in $\mathrm{g}$ per $100 \mathrm{~mL}$, $\mathrm{L}=$ length of the cuvette $(\mathrm{cm})$.

\section{Inhibition of copper-mediated human LDL and VLDL oxidation}

Inhibitory activities of phenolic extracts of finger millet dehulled grain and finger millet foods (Rotti, Pittu, Halapa, Thalapa and Porridge) against human VLDL and LDL oxidation were determined by measuring conjugated dienes $(\mathrm{CD})$ produced in the system using the method described by Chandrasekara and Shahidi, (2012b). LDL and VLDLs from human serum were isolated using HDL precipitating reagents. Pellets (LDL/VLDL precipitate) were obtained by decanting the supernatant (HDL) and suspended in phosphate buffer to obtain diluted cholesterol solution of $0.1 \mathrm{mg} / \mathrm{mL}$ protein concentration in PBS $(\mathrm{pH} 7.4,0.15 \mathrm{M} \mathrm{NaCl})$. Protein concentrations of lipoproteins were determined using the biuret reagent test. The diluted 
solution $(0.8 \mathrm{~mL})$ was mixed with $100 \mu \mathrm{L}$ of soluble extract of foods $(0.5 \mathrm{mg} / \mathrm{mL}$ in PBS $)$ in an eppendorf tube. Oxidation of LDL was initiated by adding $0.1 \mathrm{~mL}$ of $100 \mu \mathrm{M} \mathrm{CuSO}_{4}$ solution in distilled water. The mixture was incubated at $37^{\circ} \mathrm{C}$ for 24 hours. The initial absorbance $(\mathrm{t}=0)$ was read at $234 \mathrm{~nm}$ immediately after mixing and $\mathrm{CD}$ hydroperoxides formed were measured at $0,3,6,12$ and 24-hour intervals. The concentration of $\mathrm{CD}$ formed was calculated using the molar extinction coefficient of $29500 \mathrm{M}^{-1} \mathrm{~cm}^{-1}$.

\section{Statistical analysis}

All experiments were carried out in triplicates and data were reported as mean \pm standard deviation. The differences of mean values among samples were determined by one-way analysis of variance (ANOVA) followed by Tukeys Honestly Significant Difference (HSD) multiple rank tests at $\mathrm{p}=0.05$, significance level. All statistical analysis was performed by SPSS version 16 (SPSS Inc., Chicago, IL).

\section{RESULTS AND DISCUSSION}

The ability of the lipid containing foods to act against oxidation is expressed as oxidative stability of foods. TBARS values measure the level of lipid oxidation. Table 1 and 2 show the effect of the millet extracts, ferulic acid and BHA on the inhibition of TBARS on pork and fish models. In communited pork model BHA showed the highest inhibition of TBARS in the range of 80 to $94 \%$ from day 0 to end of the second week, compared to ferulic acid and millet extracts. The inhibition percentage of TBARS in pork model with added millet extracts ranged from 1 to $40 \%$ from day 0 and end of second week. In addition, the ability of TBARS production inhibition decreased with time in pork model with added millet flour or extracts. This could be due to the reduction of antioxidant power in millet extracts with the storage time. The inhibition percentage of TBARS in the fish model with added BHA and millet flour/extracts were 62 and $83 \%$ and 3 and $57 \%$, respectively on day 0 and end of second week.

Generally, the highest inhibition percentage was observed on day 0 and day 14 in pork and fish models respectively, with added millet flour/extract. Millet grain hull extracts showed high TBARS production inhibition which ranged from 56 to $63 \%$ in fish model at the end of second week . Further, the greater effect of the millet hull extract on inhibiting the production of TBARS could be due to the high phenolic content and the antioxidant activities in addition to the presence of other compounds such as, vitamin C, E, with antioxidant activities in hull extracts compared to those of dehulled grain. Previous studies also reported the ability of plant extracts to prevent the oxidation of lipids in meat (Rhee et al., 1996; Karwowska and Dolatowski, 2007). The phenolics present in natural plant extracts have strong $\mathrm{H}^{+}$donating activity. In the present study also the phenolic extracts of millet showed high antioxidant activity against lipid oxidation of the meat and fish samples. These results are in agreement with several other studies that reported natural antioxidants from plant sources could prevent the lipid oxidation of meat and meat products (Yu et al., 2002).

Table 3 shows the the effect of the millet flour/extracts, ferulic acid and BHA on production inhibition of TBARS on roasted peanut model. BHA showed the highest inhibition percentage of TBARS at the day 0 compared to ferulic acid and millet flour/extracts. Peanut sample with added proso millet dehulled grain flour showed the highest ability to prevent the production of TBARS at the end of second, third and fourth weeks. Tea catechins, as a polyphenolic flavonoid to prevent the lipid oxidation in green tea has been demonstrated in a variety of food systems (McCarthy, 2001; Nissen, 2004; Mitsumoto, 2005). Moreover, the use of millet 
phenolic extracts shows antioxidant effects similar or better than those of BHA. Polyphenolic extracts are excellent electron and proton donors, and their intermediate radicals are quite stable due to electronic delocalization phenomenon as well as the lack of position attackable by oxygen (Rhee et al., 2001). Therefore, millets can be used in peanut butter preparations to improve the quality of the product.

Table 4 shows the effect of the millet flour/extracts, ferulic acid and BHA on production inhibition of TBARS on gingelly oil model. Among those phenolic extracts of millet showed higher ability to prevent the production of TBARS reflecting their higher antioxidant activity for protection of gingelly oil against oxidation compared to ferulic acid and BHA.The highest TBARS inhibition was showed at 72 hours by phenolic extracts of finger millet hull. Compared to BHA, phenolic extracts of millet dehulled grains and hulls showed increased duration of oxidative stability in oil samples. Table 5 shows the production of CD in gingelly oil model system. Compared with the control millet hull extract added oil samples showed significantly low CD levels at 36, 48 and 72 hours. During the 0 to 24 hours of time period there were not any significant difference in the production of $\mathrm{CD}$ in oil samples with added millet hull extracts.

Results of TBARS and CD in gingelly oil model showed that phenolic extracts of millets have the ability to delay the oxidation of gingelly oil during storage. Previous studies showed that natural antioxidants from plant sources have an effect to increase the oxidative stability in oil samples (Kamali et al., 2011). Further, they showed that addition of cinnamon extracts increased the oxidative stability of sunflower oil (Kamali et al., 2011). The antioxidant potential of plant extracts is a result of not only the presence of the active phenolic compounds but also of other components present in the system. Figure 1 shows the ability of phenolic extracts of finger millet dehulled grain and finger millet foods (Rotti, Pittu, Halapa, Thalapa and Porridge) to prevent the oxidation of human VLDL and LDL in vitro. Pittu had the highest ability to prevent the production of conjugated dienes in oxidation of human VLDL and LDLs in vitro while Thalapa shows the lowest ability.

The phenolic compounds which are present in finger millet foods should have the ability to chelate cupric ions and scavenge the formed peroxyl radicals to prevent the oxidation of VLDL and LDL cholesterol in vitro (Decker et al., 2001). According to Chandrasekara and Shahidi (2011b) soluble phenolic extracts of pearl millet hulls and dehulled grain at a low concentration $(0.125 \mathrm{mg} / \mathrm{mL})$ showed 1.6 and 3.9 times higher inhibition, respectively, of LDL oxidation than that at high concentration $(0.5 \mathrm{mg} / \mathrm{mL})$. Authors explained that there is a possibility that phenolic compounds at high concentrations may complex with protein moieties of the LDL cholesterol molecules, which makes them unavailable to inhibit oxidation of cholesterol. Previous studies have shown that phenolic compounds can inhibit protein oxidation by binding of the proteins to form complexes with protein molecules (Siebert et al., 1996; Riedl and Hagerman, 2001). Therefore, the low ability of finger millet foods with high phenolic content to inhibit the oxidation of LDL and VLDL cholesterol in vitro might be due to the interactions of proteins and phenolic compounds at high concentrations of phenolics. 
Table 1. Inhibition percentage of thiobarbeturic acid reactive substances (TBARS) at different time periods in the pork model system

\begin{tabular}{|c|c|c|c|c|c|}
\hline & \multicolumn{5}{|c|}{ Inhibition percentage of TBARS } \\
\hline & Day 0 & Day 3 & & & Day 14 \\
\hline BHA & $80.09 \pm 0.11^{\mathrm{a} 1}$ & $93.66 \pm 0.38^{\mathrm{a} 2}$ & $86.94 \pm 0.69^{a 3}$ & $88.98 \pm 1.01^{\mathrm{a} 3}$ & $79.47 \pm 0.39^{\mathrm{a} 1}$ \\
\hline Ferulic acid & $14.39 \pm 0.05^{\mathrm{b} 1}$ & $23.94 \pm 0.03^{\mathrm{b} 2}$ & $19.65 \pm 2.20^{\mathrm{b} 3}$ & $27.34 \pm 2.06^{\mathrm{b} 4}$ & $3.67 \pm 1.25^{\mathrm{b} 5}$ \\
\hline Finger millet dehulled grain flour & $4.60 \pm 0.61^{\mathrm{c} 1}$ & $18.34 \pm 0.07^{\mathrm{c} 2}$ & $19.20 \pm 1.30^{\mathrm{b} 2}$ & $16.76 \pm 3.28^{\mathrm{c} 3}$ & $8.18 \pm 0.63^{\mathrm{b} 4}$ \\
\hline Foxtail millet dehulled grain flour & $10.89 \pm 0.05^{\mathrm{d} 1}$ & $9.45 \pm 0.21^{\mathrm{d} 1}$ & $21.07 \pm 2.13^{\mathrm{b} 2}$ & $24.72 \pm 2.43^{\mathrm{b} 3}$ & $12.85 \pm 0.82^{\mathrm{c} 4}$ \\
\hline Proso millet dehulled grain flour & $30.53 \pm 1.78^{\mathrm{e} 1}$ & $10.41 \pm 0.10^{\mathrm{e} 2}$ & $0.64 \pm 0.04^{c 3}$ & $13.40 \pm 1.30^{\mathrm{c} 4}$ & $8.49 \pm 0.04^{\mathrm{d} 5}$ \\
\hline Finger millet hull extract & $38.06 \pm 0.10^{\mathrm{e} 1}$ & $25.25 \pm 0.83^{\mathrm{b} 2}$ & $18.20 \pm 0.07^{\mathrm{b} 3}$ & $20.24 \pm 1.81^{\mathrm{b} 4}$ & $5.09 \pm 0.82^{\mathrm{e} 5}$ \\
\hline Foxtail millet hull extract & $4.20 \pm 0.45^{\mathrm{c} 1}$ & $18.18 \pm 0.03^{\mathrm{c} 2}$ & $7.94 \pm 0.22^{\mathrm{d} 3}$ & $23.58 \pm 3.25^{\mathrm{b} 4}$ & $6.62 \pm 1.02^{\mathrm{e} 5}$ \\
\hline Proso millet hull extract & $39.71 \pm 0.79^{\mathrm{e} 1}$ & $10.93 \pm 0.83^{\mathrm{e} 2}$ & $15.63 \pm 1.63^{\mathrm{e} 3}$ & $13.19 \pm 0.22^{\mathrm{d} 4}$ & $4.51 \pm 0.70^{\mathrm{e} 5}$ \\
\hline
\end{tabular}

Superscripts with the same letters in each column and same numbers in each row are not significantly different

Table 2. Inhibition percentage of thiobarbeturic acid reactive substances (TBARS) at different time periods in fish model system

\begin{tabular}{|c|c|c|c|c|c|}
\hline & \multicolumn{5}{|c|}{ Inhibition percentage of TBARS } \\
\hline & Day 0 & Day 3 & Day 5 & Day 7 & Day 14 \\
\hline BHA & $81.73 \pm 2.99^{\mathrm{a} 1}$ & $83.33 \pm 1.39^{\mathrm{a} 1}$ & $80.63 \pm 1.26^{\mathrm{a} 1}$ & $77.87 \pm 2.54^{\mathrm{a} 2}$ & $61.88 \pm 1.86^{\mathrm{a} 2}$ \\
\hline Ferulic acid & $18.27 \pm 2.09^{\mathrm{b} 1}$ & $18.13 \pm 0.62^{\mathrm{b} 1}$ & $5.66 \pm 0.19^{\mathrm{b} 2}$ & $20.55 \pm 0.35^{\mathrm{b} 3}$ & $4.65 \pm 0.10^{\mathrm{b} 4}$ \\
\hline Finger millet dehulled grain flour & $22.36 \pm 1.25^{\mathrm{c} 1}$ & $3.37 \pm 0.68^{\mathrm{c} 2}$ & $18.93 \pm 0.88^{\mathrm{c} 3}$ & $3.82 \pm 1.62^{\mathrm{c} 2}$ & $5.08 \pm 0.18^{\mathrm{c} 4}$ \\
\hline Foxtail millet dehulled grain flour & $38.03 \pm 0.58^{\mathrm{d} 1}$ & $5.21 \pm 0.16^{\mathrm{d} 2}$ & $16.92 \pm 1.07^{\mathrm{d} 3}$ & $7.16 \pm 1.20^{\mathrm{d} 4}$ & $2.61 \pm 0.34^{\mathrm{d} 5}$ \\
\hline Proso millet dehulled grain flour & $34.46 \pm 1.68^{\mathrm{e} 1}$ & $3.91 \pm 0.16^{\mathrm{c} 2}$ & $18.49 \pm 1.24^{\mathrm{c} 3}$ & $8.78 \pm 5.08^{\mathrm{e} 4}$ & $6.10 \pm 0.19^{\mathrm{e} 5}$ \\
\hline Finger millet hull extract & $33.38 \pm 6.22^{\mathrm{e} 1}$ & $9.12 \pm 0.16^{\mathrm{e} 2}$ & $17.48 \pm 1.53^{\mathrm{e} 3}$ & $30.70 \pm 5.06^{\mathrm{f} 4}$ & $56.10 \pm 0.04^{\mathrm{f5}}$ \\
\hline Foxtail millet hull extract & $46.35 \pm 5.23^{\mathrm{f} 1}$ & $16.83 \pm 4.55^{\mathrm{f} 2}$ & $17.61 \pm 3.60^{\mathrm{e} 3}$ & $21.61 \pm 2.22^{\mathrm{g} 4}$ & $63.13 \pm 0.14^{\mathrm{g} 5}$ \\
\hline Proso millet hull extract & $49.72 \pm 5.07^{\mathrm{g} 1}$ & $8.85 \pm 3.08^{\mathrm{g} 2}$ & $21.51 \pm 1.00^{\mathrm{f} 3}$ & $30.57 \pm 1.73^{\mathrm{f} 4}$ & $56.10 \pm 0.19^{\mathrm{f5}}$ \\
\hline
\end{tabular}

Superscripts with the same letters in each column and same numbers in each row are not significantly different 
Table 3. Inhibition percentage of thiobarbeturic acid reactive substances (TBARS) at different time periods in peanut model system

\begin{tabular}{|c|c|c|c|c|c|}
\hline & & \multicolumn{4}{|c|}{ Inhibition percentage of thiobarbeturic acid reactive substances (TBARS) } \\
\hline & Day 0 & Day 7 & Day 14 & Day 21 & Day 28 \\
\hline BHA & $63.71 \pm 0.09^{\mathrm{a} 1}$ & $23.81 \pm 3.23^{\mathrm{a} 2}$ & $43.86 \pm 1.25^{\mathrm{a} 3}$ & $24.83 \pm 4.04^{\mathrm{a} 2}$ & $25.75 \pm 3.21^{\mathrm{a} 2}$ \\
\hline Ferulic acid & $59.72 \pm 0.46^{\mathrm{b} 1}$ & $23.05 \pm 0.14^{\mathrm{a} 2}$ & $37.14 \pm 2.13^{\mathrm{b} 2}$ & $22.43 \pm 0.06^{\mathrm{b} 2}$ & $25.87 \pm 0.22^{\mathrm{b} 2}$ \\
\hline Finger millet dehulled grain flour & $57.61 \pm 0.58^{\mathrm{c} 1}$ & $24.37 \pm 0.13^{\mathrm{b} 2}$ & $45.45 \pm 3.62^{\mathrm{c} 3}$ & $29.67 \pm 5.87^{\mathrm{c} 3}$ & $34.13 \pm 0.35^{\mathrm{c} 4}$ \\
\hline Foxtail millet dehulled grain flour & $51.75 \pm 4.21^{\mathrm{d} 1}$ & $22.08 \pm 0.13^{\mathrm{c} 2}$ & $37.28 \pm 1.35^{\mathrm{d} 3}$ & $32.98 \pm 0.22^{\mathrm{d} 3}$ & $32.52 \pm 0.17^{\mathrm{d} 3}$ \\
\hline Proso millet dehulled grain flour & $49.13 \pm 1.46^{\mathrm{e} 1}$ & $27.96 \pm 0.07^{\mathrm{d} 2}$ & $45.85 \pm 1.31^{\mathrm{e} 3}$ & $33.16 \pm 0.43^{\mathrm{e} 4}$ & $37.91 \pm 1.09^{\mathrm{e} 3}$ \\
\hline Finger millet hull extract & $51.89 \pm 0.05^{\mathrm{d} 1}$ & $32.67 \pm 0.09^{\mathrm{e} 2}$ & $28.15 \pm 0.10^{\mathrm{f} 3}$ & $13.00 \pm 0.10^{\mathrm{f} 4}$ & $19.97 \pm 0.11^{\mathrm{f} 5}$ \\
\hline Foxtail millet hull extract & $55.15 \pm 0.99^{f 1}$ & $31.49 \pm 1.77^{\mathrm{f} 2}$ & $27.55 \pm 0.13^{\mathrm{g} 3}$ & $6.87 \pm 1.02^{\mathrm{g} 4}$ & $7.47 \pm 0.27^{\mathrm{g} 5}$ \\
\hline Proso millet hull extract & $33.54 \pm 2.65^{\mathrm{g} 1}$ & $28.26 \pm 0.20^{\mathrm{g} 2}$ & $28.19 \pm 0.15^{\mathrm{h} 2}$ & $9.72 \pm 1.11^{\mathrm{h} 3}$ & $2.52 \pm 1.09^{\mathrm{h} 4}$ \\
\hline
\end{tabular}

Superscripts with the same letters in each column and same numbers in each row are not significantly different

Table 4. Inhibition percentage of thiobarbeturic acid reactive substances (TBARS) at different time periods in gingelly oil model system

\begin{tabular}{|c|c|c|c|c|c|c|}
\hline & \multicolumn{6}{|c|}{ Inhibition percentage of TBARS } \\
\hline & 0 hours & 6 hours & 12 hours & 24 hours & 36 hours & 72 hours \\
\hline BHA & $12.88 \pm 3.30^{\mathrm{a} 1}$ & $4.90 \pm 0.90^{\mathrm{a} 2}$ & $5.00 \pm 1.89^{\mathrm{a} 2}$ & $6.26 \pm 1.15^{\mathrm{a} 3}$ & $9.90 \pm 2.03^{\mathrm{a} 4}$ & $18.71 \pm 1.90^{\mathrm{a} 5}$ \\
\hline Ferulic acid & $21.46 \pm 3.40^{\mathrm{b} 1}$ & $1.96 \pm 0.90^{\mathrm{b} 2}$ & $20.71 \pm 1.89^{\mathrm{b} 1}$ & $3.68 \pm 1.94^{\mathrm{b} 3}$ & $9.20 \pm 0.77^{\mathrm{b} 4}$ & $53.00 \pm 2.31^{\mathrm{b} 5}$ \\
\hline Finger millet hull extract & $28.03 \pm 2.00^{\mathrm{c} 1}$ & $13.33 \pm 0.68^{\mathrm{c} 2}$ & $32.38 \pm 2.89^{\mathrm{c} 3}$ & $23.57 \pm 1.39^{\mathrm{c} 4}$ & $41.84 \pm 1.17^{c 5}$ & $61.87 \pm 1.25^{\mathrm{c} 6}$ \\
\hline Foxtail millet hull extract & $20.20 \pm 1.10^{\mathrm{d} 1}$ & $10.59 \pm 1.18^{\mathrm{d} 2}$ & $19.29 \pm 0.71^{\mathrm{b} 1}$ & $32.04 \pm 2.53^{\mathrm{d} 3}$ & $8.68 \pm 0.80^{\mathrm{e} 4}$ & $56.12 \pm 1.90^{\mathrm{d} 5}$ \\
\hline Proso millet hull extract & $11.62 \pm 1.20^{\mathrm{e} 1}$ & $14.12 \pm 2.04^{\mathrm{e} 2}$ & $37.86 \pm 0.71^{\mathrm{d} 3}$ & $29.47 \pm 2.61^{\mathrm{e} 4}$ & $43.23 \pm 2.03^{\mathrm{f5}}$ & $54.68 \pm 0.72^{\mathrm{e} 6}$ \\
\hline
\end{tabular}

Superscripts with the same letters in each column and same numbers in each row are not significantly different 


\section{Table 5. Production of conjugated dienes (CD) in gingerlly oil model system}

\begin{tabular}{|c|c|c|c|c|c|c|c|}
\hline & & & & Time (hr) & & & \\
\hline & $\mathbf{0}$ & 06 & 12 & 24 & 36 & 48 & 72 \\
\hline Control & $9.3 \pm 1.0^{\mathrm{a} 1}$ & $11.2 \pm 2.1^{\mathrm{a} 2}$ & $12.3 \pm 0.5^{\mathrm{a} 2}$ & $12.7 \pm 0.5^{\mathrm{a} 2}$ & $13.5 \pm 1.1^{\mathrm{a} 3}$ & $11.7 \pm 0.2^{\mathrm{a} 2}$ & $14.0 \pm 1.4^{\mathrm{a} 3}$ \\
\hline BHA & $8.2 \pm 1.2^{\mathrm{a} 1}$ & $11.9 \pm 1.2^{\mathrm{a} 2}$ & $12.2 \pm 0.7^{\mathrm{a} 3}$ & $13.7 \pm 0.4^{\mathrm{b} 2}$ & $11.9 \pm 0.9^{\mathrm{b} 3}$ & $11.3 \pm 0.3^{\mathrm{a} 2}$ & $12.5 \pm 1.3^{\mathrm{b} 3}$ \\
\hline Ferulic acid & $9.1 \pm 1.0^{\mathrm{a} 1}$ & $11.7 \pm 1.1^{\mathrm{a} 2}$ & $11.7 \pm 0.7^{\mathrm{a} 2}$ & $11.9 \pm 1.2^{\mathrm{a} 2}$ & $13.6 \pm 0.7^{\mathrm{a} 3}$ & $12.4 \pm 0.4^{\mathrm{a} 4}$ & $13.9 \pm 1.0^{\mathrm{b} 3}$ \\
\hline Finger millet hull extract & $8.3 \pm 0.8^{\mathrm{a} 1}$ & $10.9 \pm 0.9^{\mathrm{a} 2}$ & $11.5 \pm 1.2^{\mathrm{a} 3}$ & $12.8 \pm 1.1^{\mathrm{a} 1}$ & $13.8 \pm 0.1^{\mathrm{a} 4}$ & $9.6 \pm 0.5^{\mathrm{b} 5}$ & $9.8 \pm 0.5^{\mathrm{c} 5}$ \\
\hline Foxtail millet hull extract & $8.1 \pm 0.2 \mathrm{a}^{1}$ & $10.2 \pm 0.8^{\mathrm{a} 2}$ & $11.7 \pm 1.1^{\mathrm{a} 1}$ & $12.7 \pm 0.9^{\mathrm{a} 3}$ & $11.80 \pm 0.5^{\mathrm{b} 1}$ & $9.4 \pm 0.4^{\mathrm{b} 2}$ & $12.4 \pm 0.8^{\mathrm{b} 3}$ \\
\hline Proso millet hull extract & $8.5 \pm 1.3^{\mathrm{a} 1}$ & $11.9 \pm 0.4^{\mathrm{a} 2}$ & $12.4 \pm 1.6^{\mathrm{a} 2}$ & $11.8 \pm 1.3^{\mathrm{a} 2}$ & $12.1 \pm 0.4^{\mathrm{b} 2}$ & $11.4 \pm 1.2^{\mathrm{a} 2}$ & $12.9 \pm 0.2^{\mathrm{b} 2}$ \\
\hline
\end{tabular}

Superscripts with the same letters in each column and same numbers in each row are not significantly different 


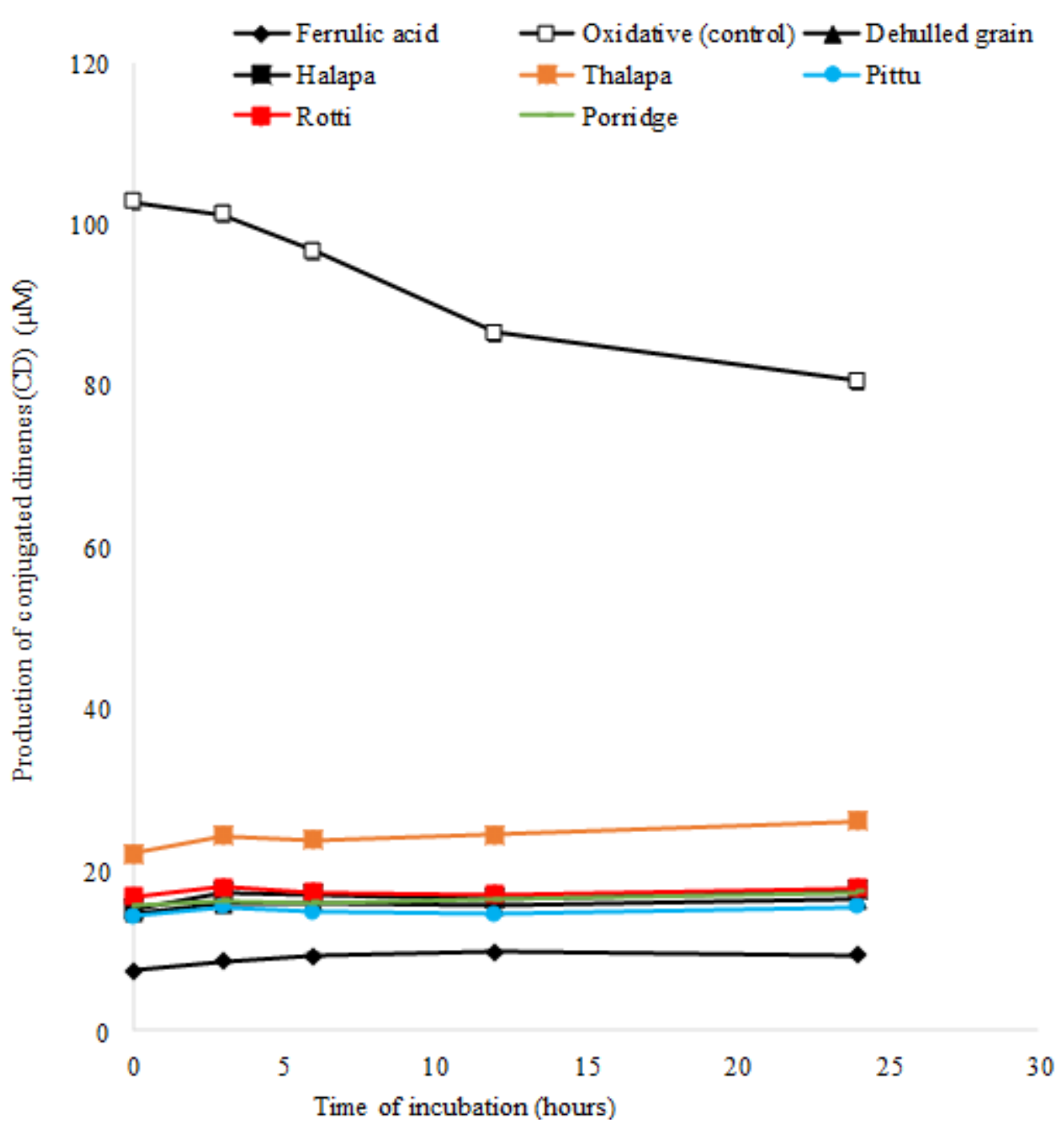

Figure 1. The production of CD in human LDL and VLDLs samples in vitro with added synthetic antioxidants and phenolic extracts of finger millet foods

Previous studies showed that plant phenolic compounds have potential to prevent the oxidation of LDL cholesterols in vitro. Phenolic compounds found in wine are potent antioxidants in inhibiting LDL oxidation in vitro (Teissedre et al., 1996; Meyer et al., 1997). According to Heinonen et al. (1998) phenolic extracts of berries, namely black berries, red raspberries, sweet cherries, blueberries, and strawberries demonstrated inhibition of human LDL oxidation. Therefore, further in vivo research is warranted to reveal the effect of millet foods consumption to prevent and control or reduce the burden of cardio vascular disease among humans. The oxidized LDL can increase the risk of initiating vascular lesions in blood vessels leading to atheroma formation. 


\section{CONCLUSIONS}

Millet grains and millet phenolic extracts act as natural sources of antioxidants in comminuted pork and fish, peanut butter and gingelly oil to prevent lipid oxidation during storage. Millet hull phenolics are potential sources of natural antioxidants which can be utilized in food industry replacing synthetic antioxidants. Further, it is worthwhile to explore the possibility of using millet hull phenolics as potential raw materials for the production of nutraceuticals to attenuate LDL cholesterol oxidation.

\section{ACKNOLEDGEMENT}

This research was supported by the National Research Council of Sri Lanka (NRC 12-096).

\section{REFERENCES}

Adeolu, A.T. and Enesi, D.O. (2013). Assessment of proximate, mineral, vitamin and phytochemical composition of plantain (Musa paradisiaca) bract - an agricultural waste. Int. j. Plant Sci. 4(7), 192-197.

Benzie, I.F.F. and Strain, J.J. (1996). Ferric reducing ability of plasma (FRAP) as a measure of "antioxidant power": the FRAP assay. Anal. Bio-chem. 239(1), 70-76.

Bopitiya, D. and Madhujith, T. (2012). Antioxidant Potential of Pomegranate (Punica granatum L.) Cultivars Grown in Sri Lanka. Trop. Agric. Res. 24(1), 71-81.

Das, S.C., Hamid, K., Bulbul, I.J., Sultana S. and Islam, S. (2010). In Vitro Antioxidant Activity of Different Parts of the Plant Diospyros discolor. Res. J. of Agric. and Biol. Sci. 6(4), $472-475$.

Dudonne S., Vitrac, X., Coutiere, P., Woillez, M. and Merillon, J.M. (2009). Comparative study of antioxidant properties and total phenolic content of 30 plant extracts of Industrial interest using DPPH, ABTS, FRAP, SOD and ORAC assays. J. Agric. Food Chem. 57(5), $1768-1774$.

Flohe, R.B and Traber M.G. (1999). Vitamin E: function and metabolism. The FASEB J. 13, $1145-1155$.

Goli, A.H, Barzegar, M. and Sahari, M.A. (2005). Antioxidant activity and total phenolic compounds of pistachio (Pistachia vera) hull extracts. Food Chem. 92, 521-525.

Haminiuk, C.W.I., Maciel, G.M., Plata-Oviedo, M.S.V. and Peralta, R.M. (2012). Invited review Phenolic compounds in fruits - an overview. Int. J. Food Sci. and Tech. 47(10), 20232044.

Jacob, A.R. (1996). Chapter 01: Introduction. pp. 1-16. In Harris, J.R. (Ed.) Subcellular Biochemistry, Ascorbic Acid: Biochemistry and Biomedical Cell Biology, vol. 25. Plenum, New York, NY, USA. 
Jayathilake, C., Rizliya, V. and Liyanage, R. (2016). Antioxidant and free radical scavenging capacity of extensively used medicinal plants in Sri Lanka. Procedia Food Sci. 6, 123-126.

Jayaweera, D.M.A. (1981). Medicinal plants (Indigenous and exotic) used in Ceylon. Part II. The National Science Foundation, Sri Lanka. pp. 228-229.

Kahkonen, M. P., Hopia, A. I., Vuorela, H. J., Rauha, J.-P., Pihlaja, K., Kujala, T. S. (1999). Antioxidant activity of plant extracts containing phenolic compounds. J. Agri. and Food Chem. 47, 3954-3962.

Kriengsak, T., Unaroj, B., Kevin, C., Luis, C. and David, H.B. (2006). Comparison of ABTS, $\mathrm{DPPH}, \mathrm{FRAP}$, and ORAC assays for estimating antioxidant activity from guava fruit extracts. J. Food Com. and Analysis. 19, 669-675.

Lanerolle, M.S.De, Priyadharshani, A.M.B., sumithraarachchi, D.B. and Jansz E.R. (2008). The carotenoids of Pouteria campechiana (Sinhala: ratalawalu). J. of the National. Science Foundation, Sri Lanka. 36(1), 95-98.

Lee, S.K. and Kader, A.A. (2000). Preharvest and postharvest factors influencing vitamin C content of horticultural crops. Postharvest Bio. and Tech. 20, 20-220.

Lee, J., Robert, W.D. and Ronald, E.W. (2005). Determination of total monomeric anthocyanin pigment content of fruit juices, beverages, natural colorants, and wines by the $\mathrm{pH}$ differential method: collaborative study. J. AOAC Int. 88(5), 1269-1278.

Lee, M.H., Jiang, C.B., Juan, S.H., Lin, R.D. and Hou, W.C. (2006). Antioxidant and heme oxygenase-1 (HO-1)-induced effects of selected Taiwanese plants. Fitoterapia. 77(2), 109115.

Lee, S., Mediani, A., Nur Ashikin, A., Azliana, A. and Abas, F. (2014). Antioxidant and $\alpha-$ glucosidase inhibitory activities of the leaf and stem of selected traditional medicinal plants. Int. Food Res. J. 21(1), 165-172.

Lie-Fen, S., Jieh-Hen, T., Je-Hsin, C., Chih-Yang, C. and Chiu-Ping, L. (2005). Antioxidant properties of extracts from medicinal plants popularly used in Taiwan. Int. J. Applied Sci. and Eng. 3(3), 195 - 202.

Lim, T.K. (2012a). Phyllanthaceae: Phylanthus acidus in Edible Medicinal and non-medicinal plants, Vol 4, Fruits, Springer Science+Business Media. London, pp. 252- 257.

Lim, T.K. (2012b). Ebinaceae: Diospyros blancoi in Edible Medicinal and non-medicinal plants, Vol 2, Fruits, Springer Science+Business Media. London, UK. pp. 421-424.

Omale J. and Ugwu C. E. (2011). Comparative studies on the protein and mineral composition of some selected Nigerian vegetables. African J. Food Sci. 5(1), 22-25.

Oviasogie, P.O., Okoro, D. and Ndiokwere, C.L. (2009). Determination of total phenolic amounts of some edible fruits and vegetables. African J. Biotech. 8(12), 2819 -2820. 
Padayatty, S., Katz, A., Wang,Y., Eck, P., Lee, J., Chen, S., Corpe, C., Dutta, A., Dutta, S. and Levine, M. (2003). Vitamin C as an antioxidant: evaluation of its role in disease prevention. J. Am. Clin. Nutr. 22(1), 18-35.

Pushpakumara, D.K.N.G. and Heenkenda, H.M.S. (2007). Chapter 06: Nelli (Amla) (Phyllanthus embilica L.). pp. 180-221. In Pushpakumara, D.K.N.G., Gunasena, H.P.M., Singh, V.P. (Ed.) Underutilized Fruit Trees in Sri Lanka Volume 1. World Agro-forestry Centre, South Asia Regional office, New Delhi, India; National Multipurpose Tree Species Research Network of Sri Lanka; Sri Lanka Council for Agricultural Research Policy, Asian Centre for Underutilized Crops, Sri Lanka.

Ramasamy, S., Wahab, N.A., Abidin, N.Z. and Manickam, S. (2011). Cytotoxicity evaluation of five Malaysian Phyllanthaceae species on various human cancer cell lines. J. Med. Plant Res. 5(11), 2267-2273.

Safaa, Y. Q., Abo-khatwa, A.N. and Lahwa, M.A.B. (2010). Screening of antioxidant activity and phenolic content of selected food items cited in the Holly Quran. Europ. J. Biol. Sci. 2(1), 40-51.

Shofian, N.M., Hamid, A.A., Osman, A., Saari, N., Anwar, F., Dek, M. S. P. and Hairuddin, M.R. (2011). Effect of freeze-drying on the antioxidant compounds and antioxidant activity of selected tropical fruits. Int. J. Mol. Sci. 12, 4678-4692.

Silva, K.D.R.R. and Sirasa M.S.F. (2018). Antioxidant properties of selected fruit cultivars grown in Sri Lanka. Food Chem. 238, 203-208.

Su, L., Yin, J.J., Charles, D., Zhou, K., Moore, J. and Yu, L. (2007). Total Phenolic contents, chelating capacities and radical-scavenging properties of black peppercorn, nutmeg, hrosewhip, cinnamon and oregano leaf. J. Food Chem. 100(3), 990-997.

Surveswaran, S., Cai, Y.Z., Cork, H. and Sun, M. (2007). Evaluation of natural phenolic antioxidant from 133 Indian medicinal plants. Food Chem. 102, 938-953.

Vidhan, J., DerMarderosian, A. and John, R.P. (2010). Anthocyanins and polyphenol oxidase from dried arils of pomegranate (Punica granatum L.). J. Food Chem. 118(1), 11-16.

Wang, S.Y and Zheng, W. (2001). Effect of plant growth temperature on antioxidant capacity in strawberry, J. Agric. Food Chem. 49, 4977-4982.

Wojdyło, A., Oszmianski, J. and Czemerys R. (2007). Antioxidant activity and phenolic compounds in 32 selected herbs. Food Chem. 105, 940-949.

Yu, L., Perret, J. and Davy, B., Wilson, J. and Melby, C.L. (2002). Antioxidant properties of cereal products. J. Food Sci. 67(7), 2600-2603.

Zhou, K. and Yu, L. (2004). Antioxidant properties of bean extracts from Trego wheat grown at different locations. J. Agri. Food Chem. 52(5), 1112-1117. 
Kumari et al.

Zulaikha, A.G.S., Mediani, A., Khoo, L.W., Lee, S.Y., Leong, S.W. and Abas, F. (2017). Effect of different drying methods and solvent ratios on biological activities of Phyllanthus acidus extracts. Int. Food Res. J. 24(1), 114-120. 